\title{
Optimal Power Flow Solution with Maximum Voltage Stability
}

\author{
Dr. Ahmed Nasser B. Alsammak, PhD. \\ Electrical Engineering Department \\ Collage of Engineering \\ University of Mosul \\ Email: Ahmed_Alsammak2003@yahoo.com
}

\begin{abstract}
This paper presents an Optimal Power Flow (OPF) formulation that is based on multi-objective optimization methodology, which can minimize both of operating costs and losses and it would at same time result in maximizing the distance to voltage collapse. A "Maximum Distance to Voltage Collapse" algorithm, which incorporates constraints on the current operating condition, is firstly presented, while OPF formulations which incorporate voltage stability criteria is secondly presented. The algorithm built on Matlab-Simulink is tested on an IEEE 6-bus test system using a standard power flow model, where the effect of maximum loading point limits is demonstrated.
\end{abstract}

Keywords: Voltage Stability, Voltage Collapse, Optimal Power Flow and MatlabSimulink.

$$
\begin{aligned}
& \text { حل سريان الحمل الأمثل مع أعلى استقرارية للقولتية } \\
& \text { د.أحمد نصر بهجت السماك } \\
& \text { قسم الهندسـة الكهربائيسة } \\
& \text { كلية الهندسـة/جامعة الموصل } \\
& \text { المستلخص النفا }
\end{aligned}
$$

يقدم هذا البحث صيغة لحل سريان الحمل بطريقة مثلى واعتمادا على أساسيات مهمة بحيث تكون كلفة التشغيل

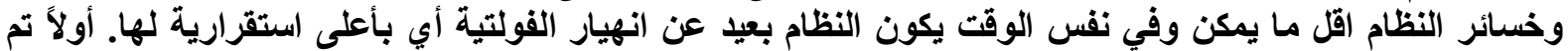

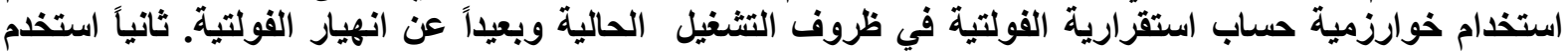

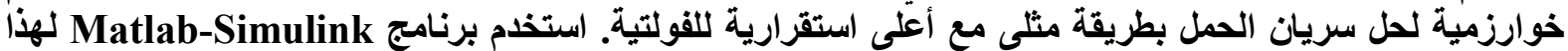

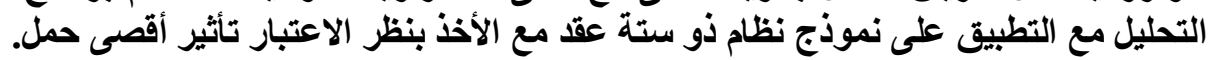




\section{List of symbols:}

$\mathrm{V}=$ Amplitude terminal load voltage (p.u.).

$\delta=$ Internal terminal load voltage angle in degree.

$\mathrm{C}_{\mathrm{S}}$ and $\mathrm{C}_{\mathrm{D}}=$ vectors of supply and demand bids in $\$ / \mathrm{MWh}$.

$\mathrm{P}_{\mathrm{ij}}$ and $\mathrm{P}_{\mathrm{ji}}=$ powers flowing through the lines in both directions in MW.

$\mathrm{P}_{\mathrm{S}}$ and $\mathrm{P}_{\mathrm{D}}=$ bounded supply and demand power bids in MW.

$\lambda$ and $\lambda_{\mathrm{c}}=$ loading and critical loading parameters.

$\mathrm{TTL}=$ Total transaction level $\left(T=\sum_{i} P_{L i}\right)$.

$\mathrm{Q}_{\mathrm{G}}=$ Generator reactive powers.

"c" = Introduced to represent the system at the limit or "critical" conditions.

$\mathrm{P}_{\mathrm{G} 0}$ and $\mathrm{P}_{\mathrm{L} 0}=$ Stand for generator and load powers.

LMPs $=$ Lagrangian multipliers associated with the active power equations.

\section{Introduction:}

Optimal Power Flow (OPF) have been widely used in planning and real-time operation of power systems for both active and reactive power dispatch to minimize generation costs and system losses and to improve voltage profiles [1]. Typically, these two problems have been assumed decoupled and thus treated independently. However, as the system operates closer to its stability limits, such as its voltage collapse point, due to market pressures, this assumption cannot be applied any longer, and hence there is a need to consider these limits within the OPF. By including this stability limits in the OPF problem, optimization procedures can also be used to improve the overall system security while accounting at the same time for the costs associated with it, which is becoming an important issue in open electricity markets.

Voltage collapse in electric power systems has recently received significant attention in the literature (see, e.g., [2] for a synopsis); this has been attributed to increases in demand, resulting in operation of electric power systems near their stability limits. A number of physical mechanisms have been identified as possibly leading to voltage collapse. From a mathematical perspective, voltage collapse has been viewed as arising from a bifurcation of the power system governing equations as a parameter is varied through some critical value.

Dobson and Chiang [3] presented a mechanism for voltage collapse, which postulates that this phenomenon occurs at a saddle node bifurcation of equilibrium points. They employed the Center Manifold Theorem to understand the ensuing dynamics. The saddle node bifurcation mechanism for voltage collapse postulated in Ref.[2].

New voltage stability analysis techniques are being introduced using optimization methods that determine optimal control parameters to maximize load margins to a voltage collapse [4] and [5]. In Ref.[6], optimal shunt and series compensation parameter settings are calculated to maximize the distance to a saddle-node bifurcation, which can be associated in some case with voltage collapse. In Ref. [7], a voltage collapse point computation problem is formulated as an optimization problem, allowing the use of optimization techniques and tools. In [8], the reactive power margin from the point of view of voltage collapse is determined using interior point methods; the authors used a barrier function to incorporate limits, interior point methods are given in details in Ref [9]. F. Alvarado and etal are 
determining the closest bifurcation to the current operating point on the hyperspace of bifurcation points [10].

This paper presents an Optimal Power Flow (OPF) algorithm that incorporates voltage stability margins. Two main issues are considered: first, how limits affect maximum loading point computations; and second, how to include voltage stability criteria in the original OPF objective function. The role of limits, and power flow dependent and independent variables are demonstrated using a Lagrangian analysis. An OPF algorithm is then reformulated to increase the emphasis on voltage stability requirements as an operating point moves closer to voltage collapse. Matlab-simulink based PSAT [11] is used for all above analysis resulting in OPF with maximum voltage stability.

\section{Optimal Power Flow and Optimization Techniques:}

The optimal power flow problem was introduced in the early 1965 by DOMMEL and etal [1] and has grown into a powerful tool for power system operation and planning. In general, the optimal power flow problem is a non-linear programming (NLP) problem that is used to determine the "optimal" control parameter settings to minimize a desired objective function, subject to certain system constraints [11]. OPF problems are generally formulated as nonlinear programming problems (NLP) as follows:

\section{A. Maximization of the Benefit:}

The OPF-based approach is basically a non-linear constrained optimization problem, and consists of a scalar objective function and a set of equality and inequality constraints. A typical OPF-based market model can be represented using the following security constrained optimization problem [11]:

Min. $-\left(\sum_{\mathrm{i}=0}^{\mathrm{n}} \mathrm{CDi}\left(\mathrm{P}_{\mathrm{Di}}\right)-\sum_{\mathrm{i}=0}^{\mathrm{n}} \mathrm{CSi}\left(\mathrm{P}_{\mathrm{Si}}\right)\right) \rightarrow$ Social benefit

$\mathrm{g}(\delta, \mathrm{V}, \mathrm{QG}, \mathrm{Ps}, \mathrm{PD})=0 \rightarrow \mathbf{P F}$ equations

$0 \leq \mathrm{Ps} \leq \mathrm{PS}_{\max } \rightarrow$ Supply bid blocks

$0 \leq \mathrm{PD} \leq \mathrm{P}_{\mathrm{Dmax}} \rightarrow$ Demand bid blocks

$\left|\mathrm{P}_{\mathrm{ij}}(\delta, \mathrm{V})\right| \leq \mathrm{P}_{\mathrm{ij} \max } \rightarrow$ Power transfer limits.

$\left|\mathrm{P}_{\mathrm{ji}}(\delta, \mathrm{V})\right| \leq \mathrm{P}_{\mathrm{jimax}}$

$\mathrm{Q}_{\mathrm{Gmin}} \leq \mathrm{QG}_{\mathrm{G}} \leq \mathrm{QG}_{\mathrm{Gmax}} \rightarrow$ Gen. Q limits.

$\mathrm{V} \min \leq \mathrm{V} \leq \mathrm{V} \max \rightarrow \mathrm{V}$ "security" limits.

$\mathrm{P}_{\mathrm{ij}}$ and $\mathrm{P}_{\mathrm{ji}}$ represent the powers flowing through the lines in both directions, and model system security by limiting the transmission line power flows, together with line current $\mathrm{I}_{\mathrm{ij}}$ and $\mathrm{I}_{\mathrm{ji}}$ thermal limits and bus voltage limits. In this model, which is typically referred to as a security constrained OPF, $\mathrm{P}_{\mathrm{ij}}$ and $\mathrm{P}_{\mathrm{ji}}$ limits are obtained by means of off-line angle and/or voltage stability studies. In practice, these limits are usually determined based only on power flow based voltage stability studies and can be determined using the continuation power flow routines PSAT.

\section{B. Maximization of the Distance to Collapse:}

The following optimization problem is implemented to properly represent system security with voltage stability conditions, based on what was proposed in Ref. [11]:

Min. $G=-\lambda_{\mathrm{c}}$

s.t. $\mathrm{g}(\delta, \mathrm{V}, \mathrm{QG}, \mathrm{Ps}, \mathrm{PD})=0 \rightarrow \mathrm{PF}$ equations

$\mathrm{g}\left(\delta_{\mathrm{c}}, \mathrm{V}_{\mathrm{c}}, \mathrm{Q}_{\mathrm{Gc}}, \lambda \mathrm{c}, \mathrm{P}_{\mathrm{S}}, \mathrm{P}_{\mathrm{D}}\right)=0 \rightarrow$ Max load PF eqs. 
$\lambda_{\text {cmin }} \leq \lambda_{c} \leq \lambda_{\text {cmax }} \rightarrow$ loading margin

$0 \leq \mathrm{P}_{\mathrm{S}} \leq \mathrm{P}_{\mathrm{Smax}} \rightarrow$ Sup. bid blocks

$0 \leq \mathrm{P}_{\mathrm{D}} \leq \mathrm{P}_{\text {Dmax }} \rightarrow$ Dem. bid blocks

$\mathrm{I}_{\mathrm{ijj}}(\delta, \mathrm{V}) \leq \mathrm{I}_{\mathrm{ijmax}} \rightarrow$ Thermal limits

$\mathrm{I}_{\mathrm{ji}}(\delta, \mathrm{V}) \leq \mathrm{I}_{\mathrm{jimax}}$

$\mathrm{I}_{\mathrm{ij}}\left(\delta_{\mathrm{c}}, \mathrm{V}_{\mathrm{c}}\right) \leq \mathrm{I}_{\mathrm{ijmax}}$

$\mathrm{I}_{\mathrm{ji}}\left(\delta_{\mathrm{c}}, \mathrm{V}_{\mathrm{c}}\right) \leq \mathrm{I}_{\mathrm{jimax}}$

$\mathrm{Q}_{\mathrm{Gmin}} \leq \mathrm{Q}_{\mathrm{G}} \leq \mathrm{Q}_{\mathrm{Gmax}} \rightarrow$ Gen. Q limits

$\mathrm{Q}_{\mathrm{Gmin}} \leq \mathrm{Q}_{\mathrm{Gc}} \leq \mathrm{Q}_{\mathrm{Gmax}}$

$\mathrm{V}_{\min } \leq \mathrm{V} \leq \mathrm{V}_{\max } \rightarrow \mathrm{V}$ "security" lim.

$\mathrm{V}_{\text {min }} \leq \mathrm{Vc} \leq \mathrm{V}_{\text {max }}$

In this case, a second set of power flow equations and constraints with a subscript "c" is introduced to represent the system at the limit or "critical" conditions associated with the maximum loading margin $\lambda_{\mathrm{c}}$ in p.u., where $\lambda$ is the parameter that drives the system to its maximum loading condition. The maximum or critical loading point could be either associated with a thermal or bus voltage limit or a voltage stability limit (collapse point) corresponding to a system singularity (saddle-node bifurcation) or system controller limits like generator reactive power limits (limit induced bifurcation) [2]. For the current and maximum loading conditions, the generator and load powers are defined as follows [5]:

$\mathrm{P}_{\mathrm{G}}=\mathrm{P}_{\mathrm{G} 0}+\mathrm{P}_{\mathrm{S}}$

$\mathrm{P}_{\mathrm{L}}=\mathrm{P}_{\mathrm{L} 0}+\mathrm{P}_{\mathrm{D}}$

$\mathrm{P}_{\mathrm{Gc}}=\left(1+\lambda_{\mathrm{c}}+\mathrm{k}_{\mathrm{Gc}}\right) \mathrm{P}_{\mathrm{G}}$

$\mathrm{P}_{\mathrm{Lc}}=\left(1+\lambda_{\mathrm{c}}\right) \mathrm{P}_{\mathrm{L}}$

where $\mathrm{P}_{\mathrm{G} 0}$ and $\mathrm{P}_{\mathrm{L} 0}$ stand for generator and load powers which are not part of the market bidding (e.g. must-run generators, inelastic loads), and $\mathrm{k}_{\mathrm{Gc}}$ represents a scalar variable which distributes system losses associated only with the solution of the critical power flow equations in proportion to the power injections obtained in the solution process (distributed slack bus model). It is assumed that the losses corresponding to the maximum loading level defined by $\lambda_{c}$ in equation (2) are distributed among all generators. Observe that power directions equation (3) used in the voltage stability constrained OPF differ from equation (2).

\section{Test Algorithm and Numerical Simulations}

In this work, test programs for the optimal power flow were created by MatlabPSAT. Figure (1) shows the simplified flow chart for OPF. Appendix (A) and Appendix (B) give some computational details for OPF program results. The goal was to develop a method that would reach an acceptable near

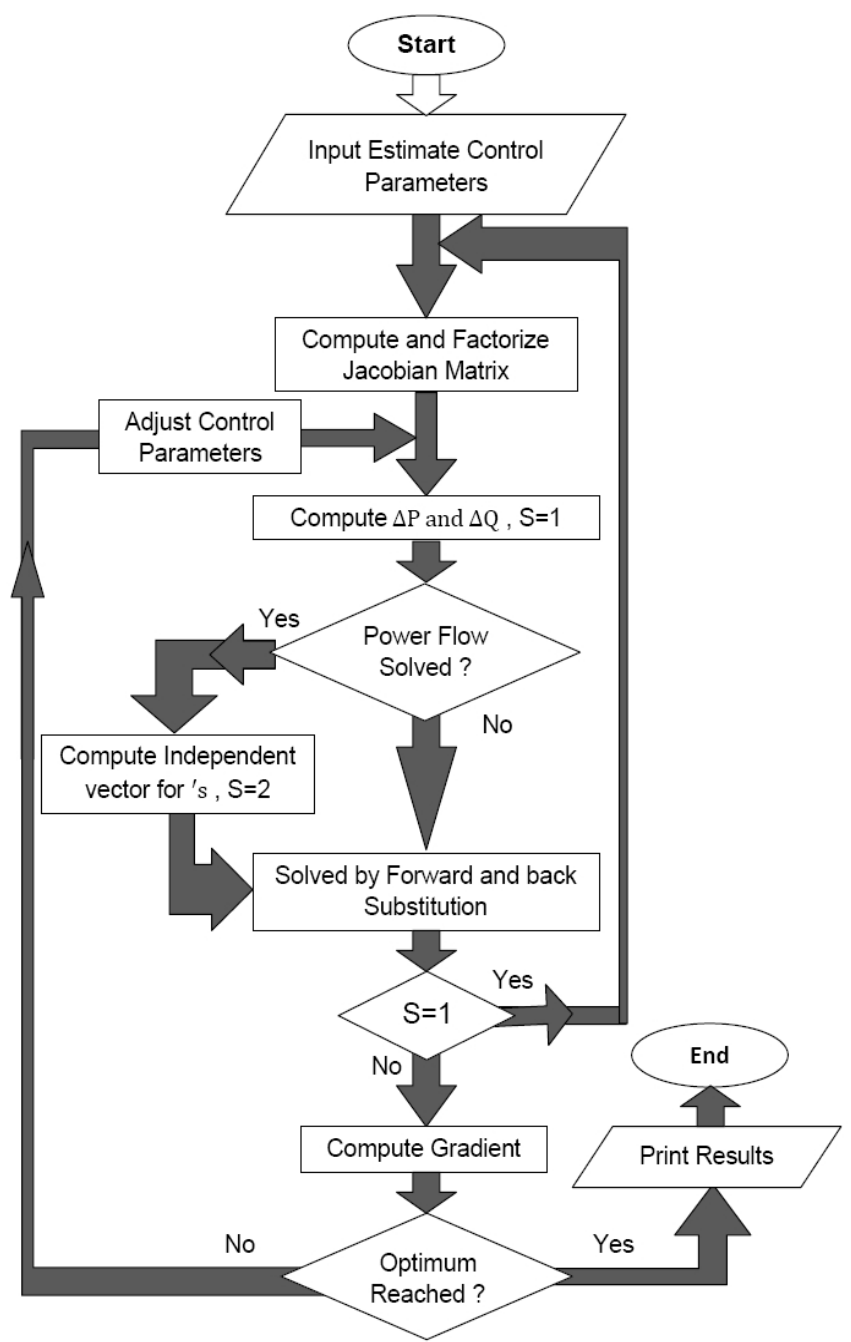

Figure (1) Simplified flow chart for OPF. 
optimum as fast as possible, rather than a method with extremely high accuracy at the expense of computer time. There is no need to determine the control parameters (real \& reactive powers) more accurately than they can be adjusted and measured in the actual system.

The maximum distance to collapse and OPF with voltage stability constraints algorithms presented in previous sections are tested on a 6-bus, 3-generator system that is based on the IEEE 6-bus test system shown in Figure (2), which represents three generation companies (GENCOs) and three energy service companies (ESCOs) that provide linear supply and demand bids, respectively. The complete set of data for this system is provided in Ref [11]. Transmission line limits are not included in the inequality constraints. All the results discussed here were obtained using the Matlab-based PSAT program, which makes use of a primal-dual IP method based on a Mehrotra's predictor-corrector technique and a CPF routine. Figure (3) shows IEEE 6-bus test system as modeled in Matlab-PSAT

On a Pentium 4, $3.1 \mathrm{GHz}$, with $2 \mathrm{~GB}$ of RAM, the six-bus test cases took about 6sec of CPU time for the elastic load case. These results show that the computational burden of the proposed technique can readily fit the requirements of realistic daily or hourly markets.

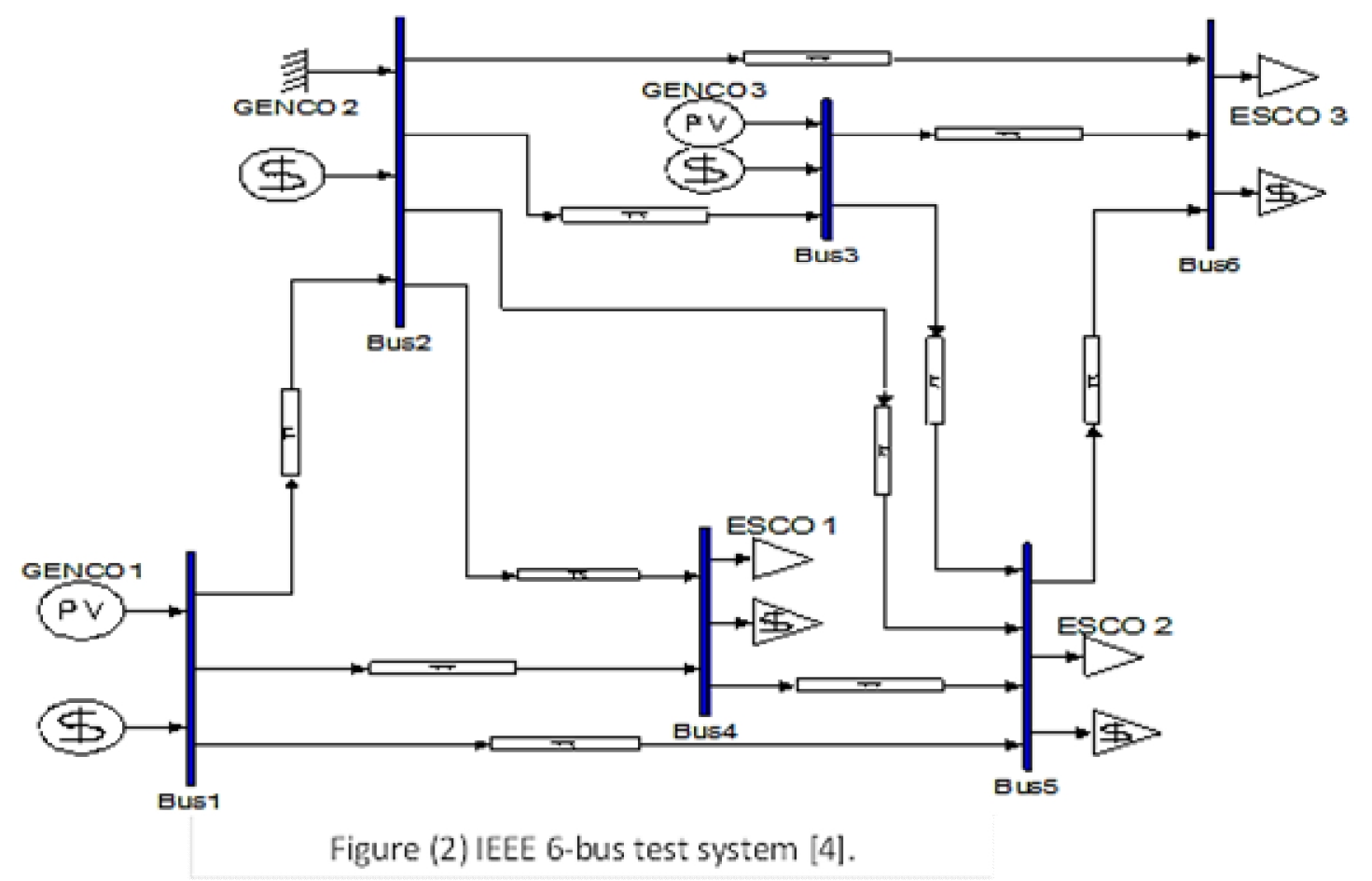

\section{Results and Discussion}

The OPF formulations (1), (2), and (3) were implemented in MATLAB and applied to an IEEE 6-bus system, shown in Figure (2) which has one infinite bus (bus\#2), two generators and three loads.

First, a "Maximum Distance to Voltage Collapse" must be determined by finding the relation between bus voltages and loading parameter, i.e. nose curve, as shown in Figure (4). Any change on loading parameters resulting in changing in each bus voltage that is not serious except at weak buses, where any change must be under focusing so it is very necessary to determine weak buses. Weak buses can be determined by finding participation factors and 
Eigen-values where weak buses are those buses that show higher participation factors to the smallest Eigen-values. Appendix (C) shows all voltage stability analysis results. From these results, it can be concluded that weak bus of this system is bus number five (Bus\#5), where higher participation factor at Eig Jlfd2 $=0.80321$ and smallest Eigen-value (Eig Jlfd2) $=$ 10.4575 .

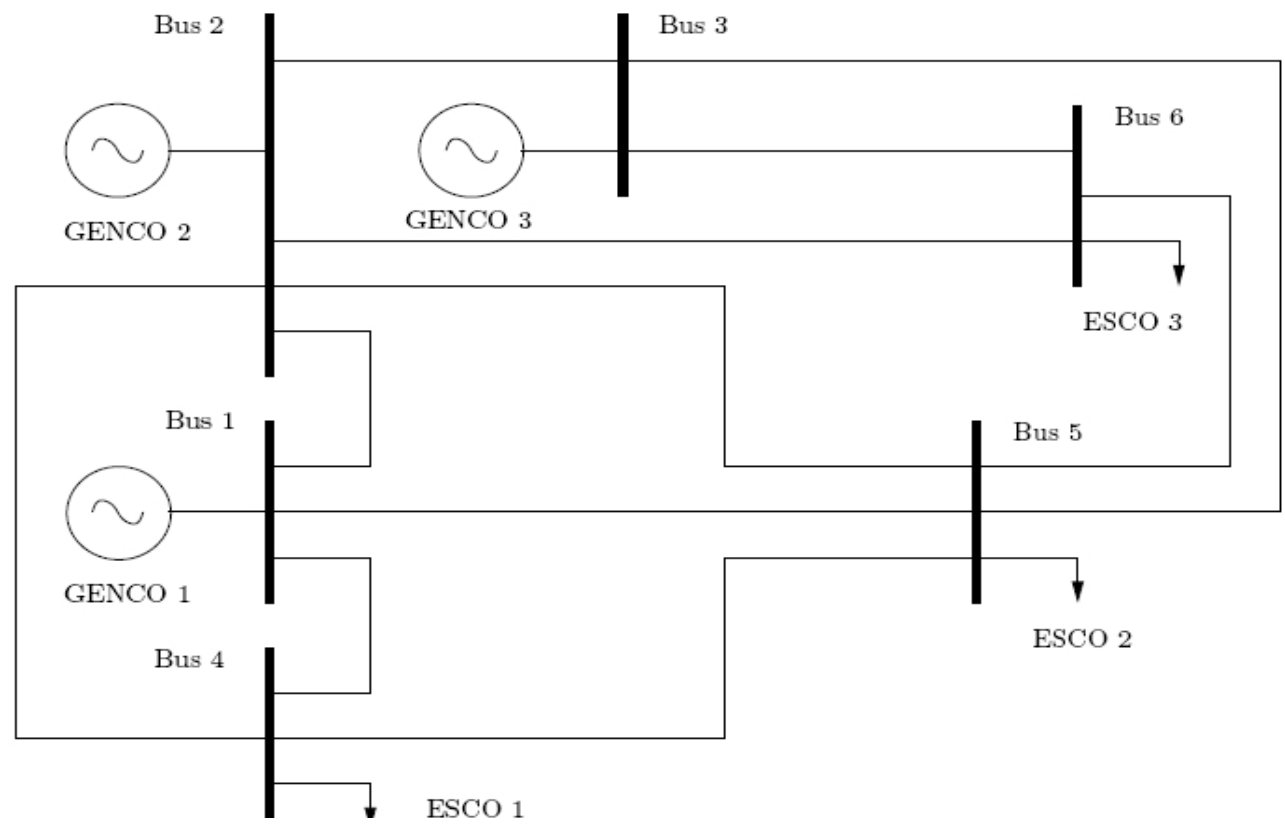

Figure (3) IEEE 6-bus test system as modeled in PSAT [4].

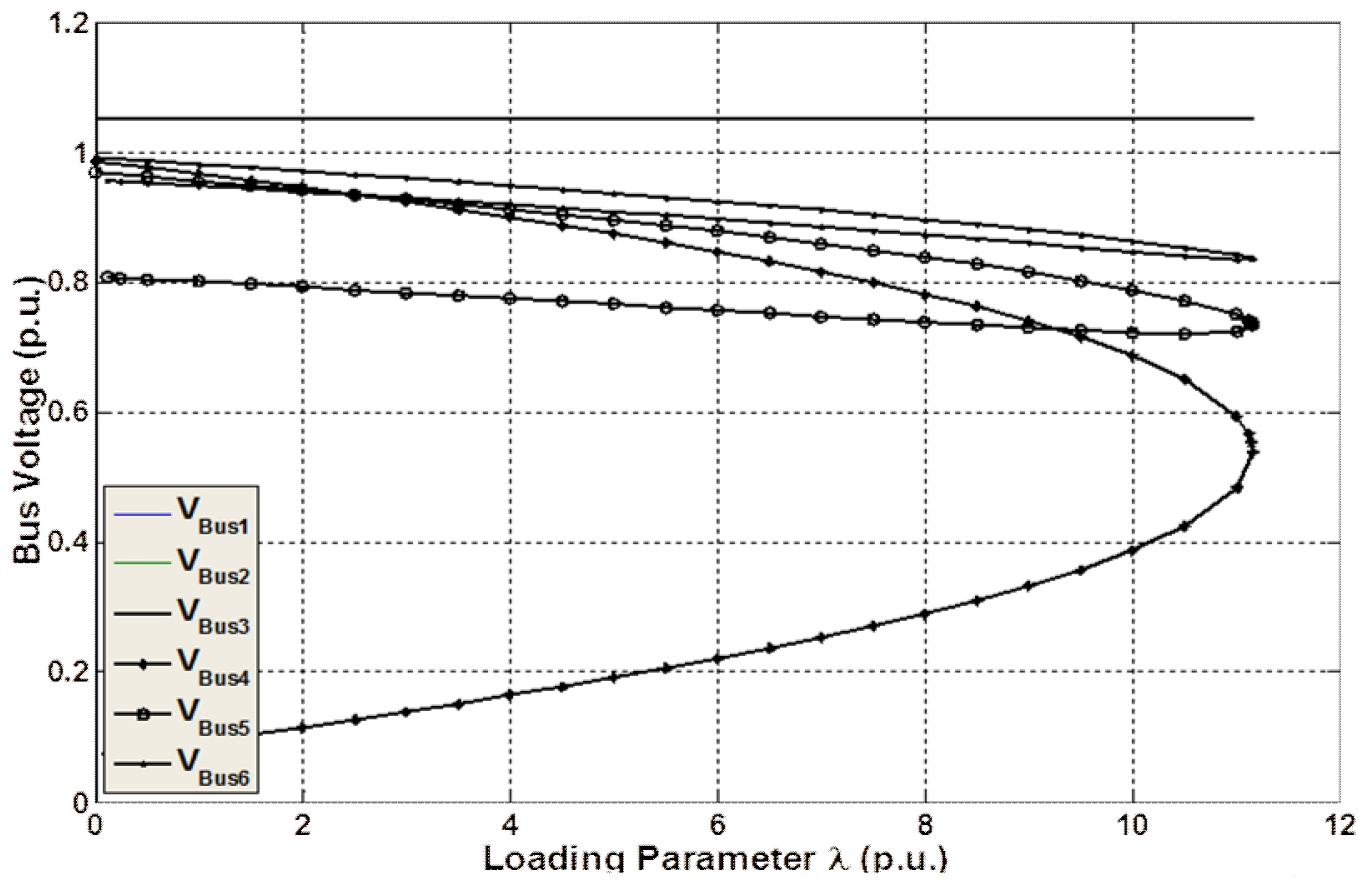

Figure (4) Voltages Buses variation vs loading parameters. 
Second, an OPF solution using formulations (1), (2) and (3), where the Lagrangian multipliers associated with the active power equations are the LMPs. Figure (5) shows the relation between LMPs $(\$ / \mathrm{MWh})$ and critical loading parameter $\left(\lambda_{\mathrm{c}}\right)$ for varying reactive load.

At the current operating conditions at weak bus, Load bus $\# 5=0.9+j 0.6$ p.u., if the reactive power increases to $\mathrm{Q}=0.75$ p.u. the system would thus go to unstable margin. So reactive power $\mathrm{Q}=0.6 \mathrm{p}$.u. would thus be a suitable load and maximum critical loading parameters will be $\lambda \mathrm{c}=0.8$.

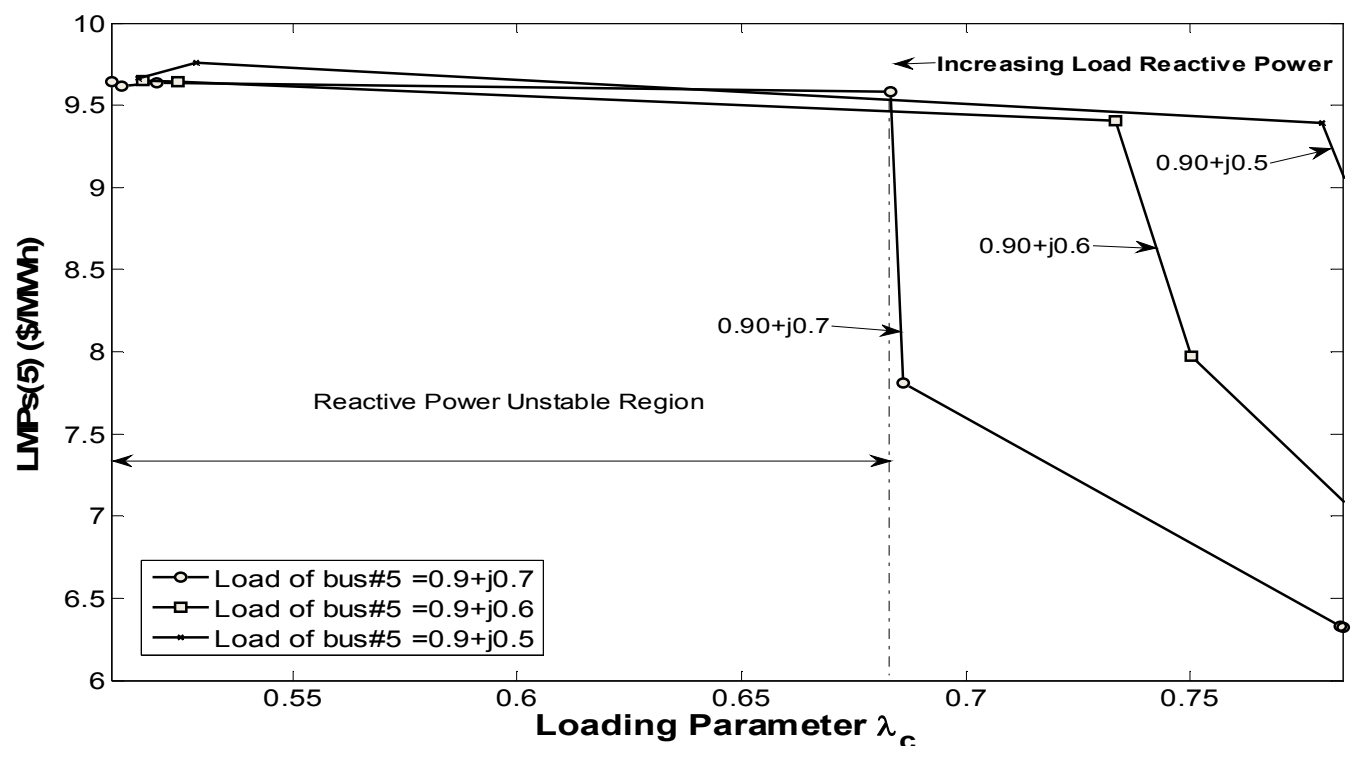

Figure (5) $\operatorname{LMPs}(5)$ variation vs critical loading parameter $(\lambda c)$.

Appendix (B) depicts the results for the VSC-OPF-based market problem with $\lambda c=0$, i.e., for the base case solution; these results are in accordance with results presented in [4], as expected. The initial solution with $\lambda_{c}=0$ is then used as the first point of the CPF-OPF algorithm. Figure (6) depicts the total transaction level TTL $\left(T=\Sigma_{i} P_{L i}\right)$ for the six-bus system as a function of the loading parameter $\left(\lambda_{c}\right)$ obtained with the proposed technique.

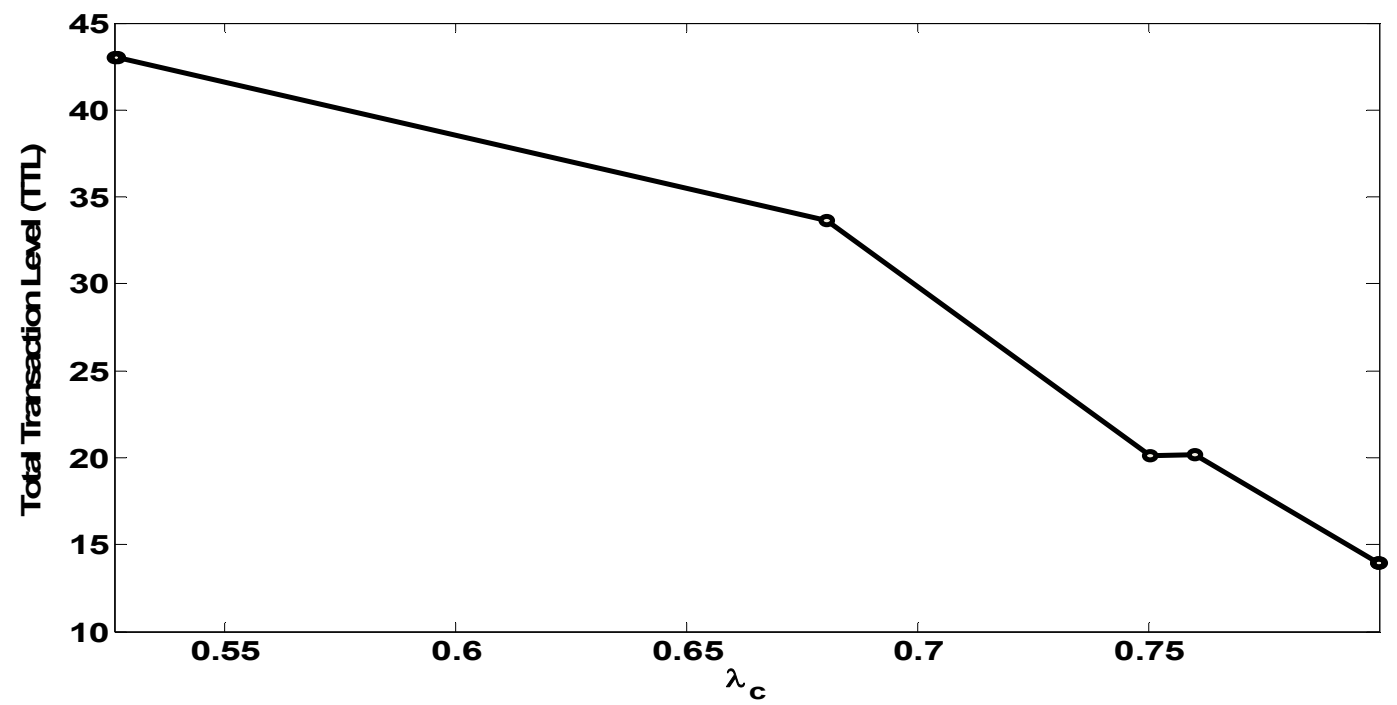

Figure (6) Total transaction level TTL $\left(\mathrm{T}=\sum_{\_} \mathrm{iP} \_\mathrm{Li}\right)$ for the six-bus system vs loading parameter $(\overline{\lambda c})$. 
Figure (8) shows three dimension variation of weak bus\#5 $\mathrm{V}_{\text {Bus\#5 }} \& \mathrm{LMP}_{\text {Bus\#5 }}$ versus weighting factor $(\omega)$ illustrates the accepted power bids for the six-bus example with elastic demand with respect to system demand changes represented by the weighting parameter $(\omega)$, illustrating the effect of security limits (system congestion) on market conditions. It is to be observed that the overall total transaction level decreases, which is to be expected, since as the load increases, the system would hence get closer to its security margins, i.e., gets more congested, and hence, transactions levels decrease to meet the security constraints due to the elasticity of the loads; the power bids at each bus, on the other hand, may increase or decrease as the load increases, depending on the active security constraints. It is interesting to observe in Figure (8-c) that the LMPs decrease as the system demand, and hence, congestion levels increase; this is due to the load elasticity, which allows market participants to properly respond to increased system congestion, which is not the case for inelastic demand. Observe also that at the loading parameter value $\lambda c=0.74$, LMPs decrease below the minimum power supply price bid of 7.2 \$/MWh (As given in Appendix B); this is due to the OPF constraints forcing the system to work at the power levels that can maintain the required loading margin. Thus, market solutions for $\lambda_{c}>0.74$ are likely to be discarded by the market participants, as the LMPs are smaller than the cheapest supply bid. The algorithm was stopped at $\lambda c=0.8$, due to the fact that further increases in the loading parameter; would result in values that are not relevant for market operations.

Figure (7), Figure (8) and Figure (9) depict the accepted bids and the LMPs, respectively, for the six-bus example with inelastic demand. Notice that the demand bids were fixed at the values illustrated in Appendix (B), which lead to a constant total transaction level MW. Since the demand is constant, the increase in the loading margin leads to a redistribution of generated powers and, thus, to more expensive transactions, as one would expect. Furthermore, the variation of power levels are consistent with the signs of the sensitivities, as depicted in Figure (9).

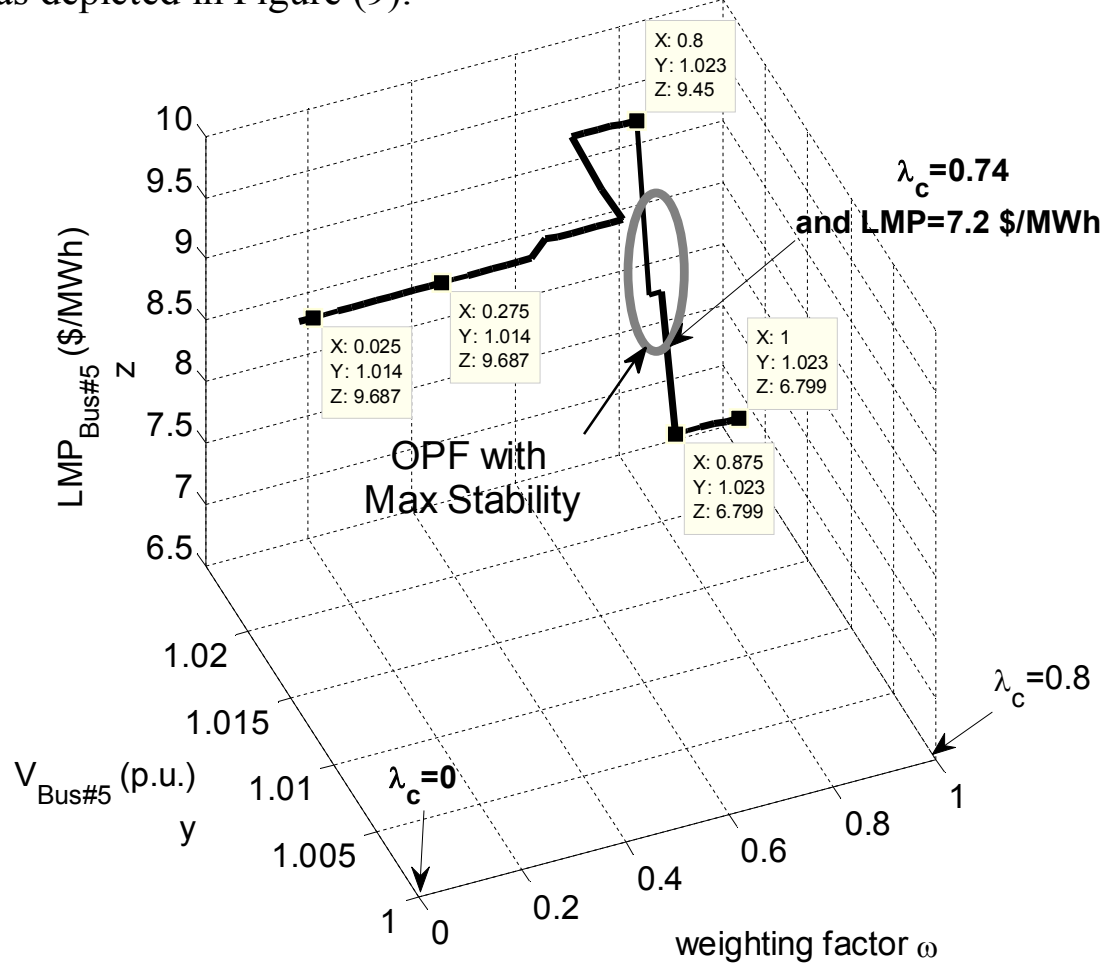

Figure (7) Three dimension variation of $\mathrm{V}_{\mathrm{Bus} \# 5}$ \& LMP Bus\#5 vs weighting factor $(\omega)$. 


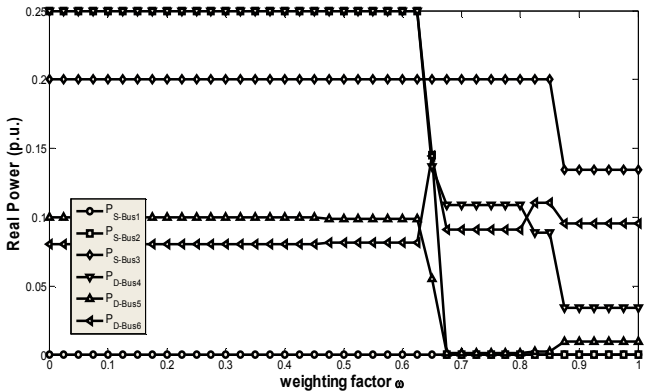

(a)

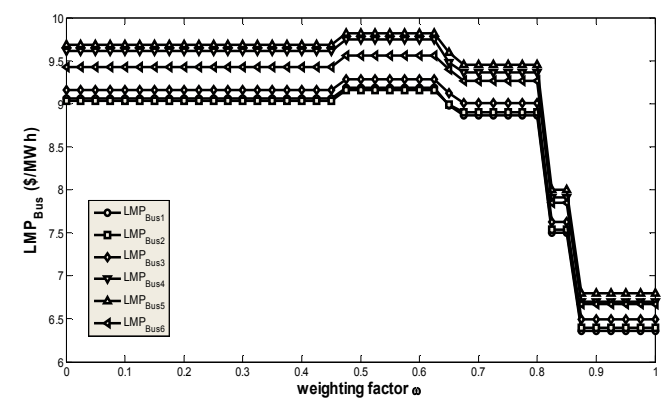

(c)

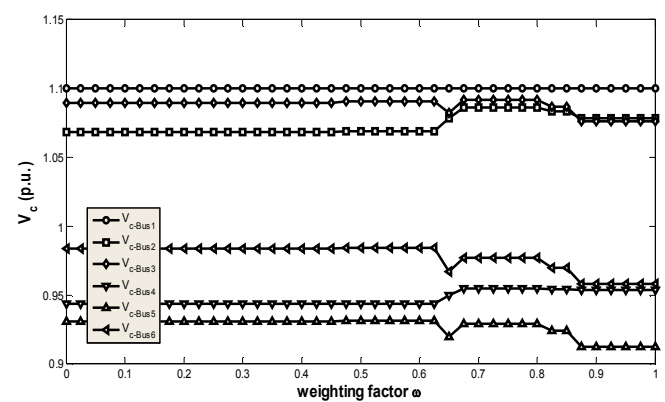

(e)

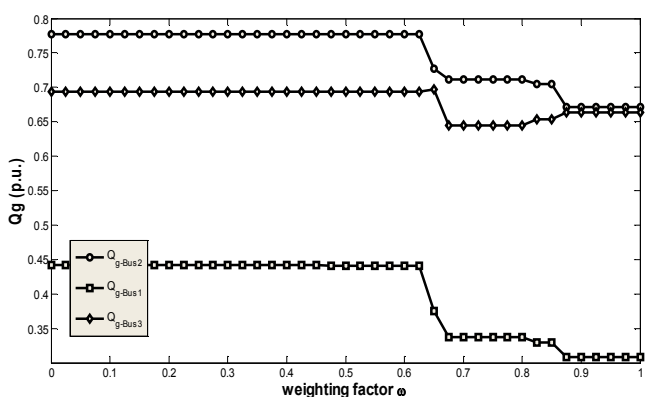

(g)

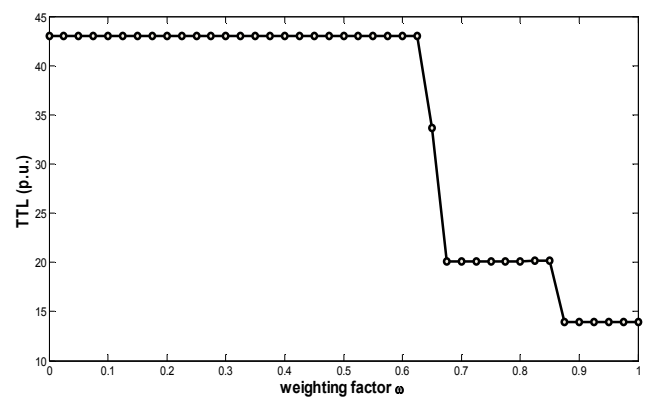

(i)

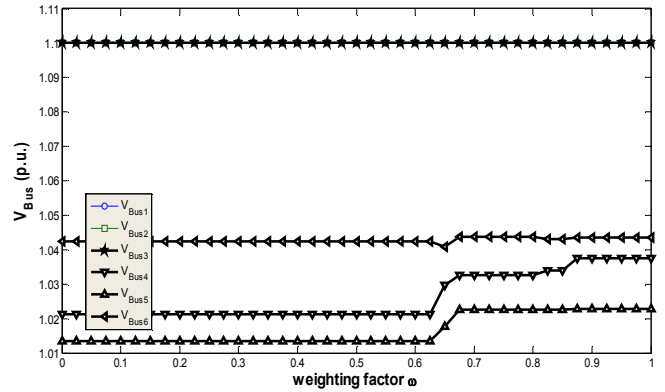

(b)

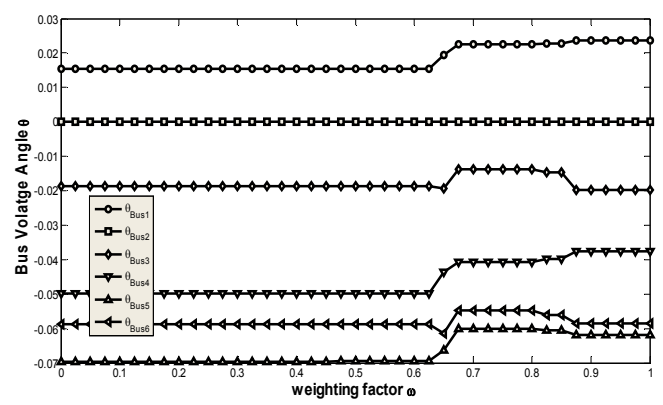

(d)

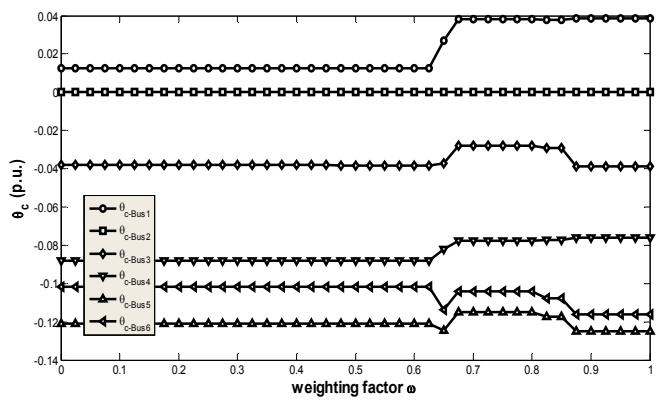

(f)

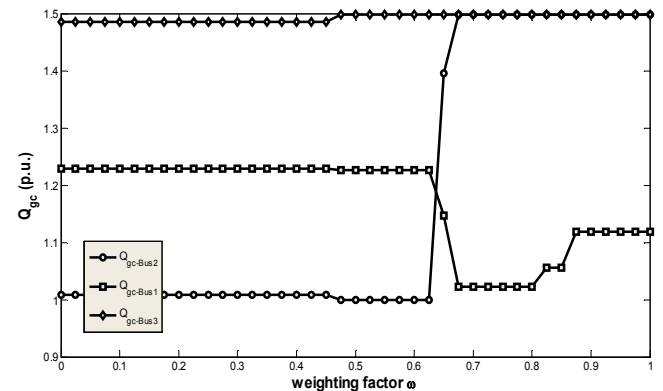

(h)

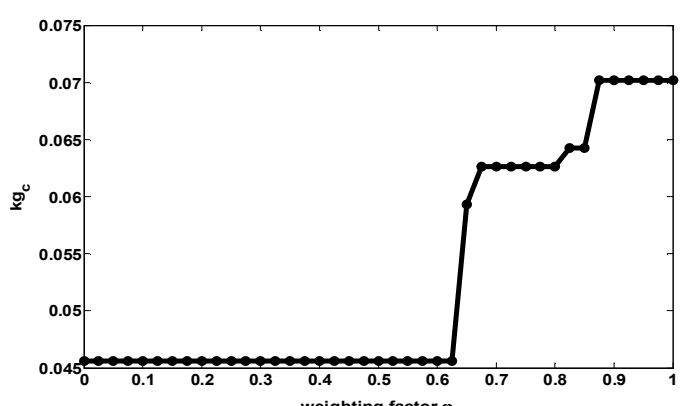

(j)

Figure (8) All system variation for OPF vs weighting factor $(\omega)$. 


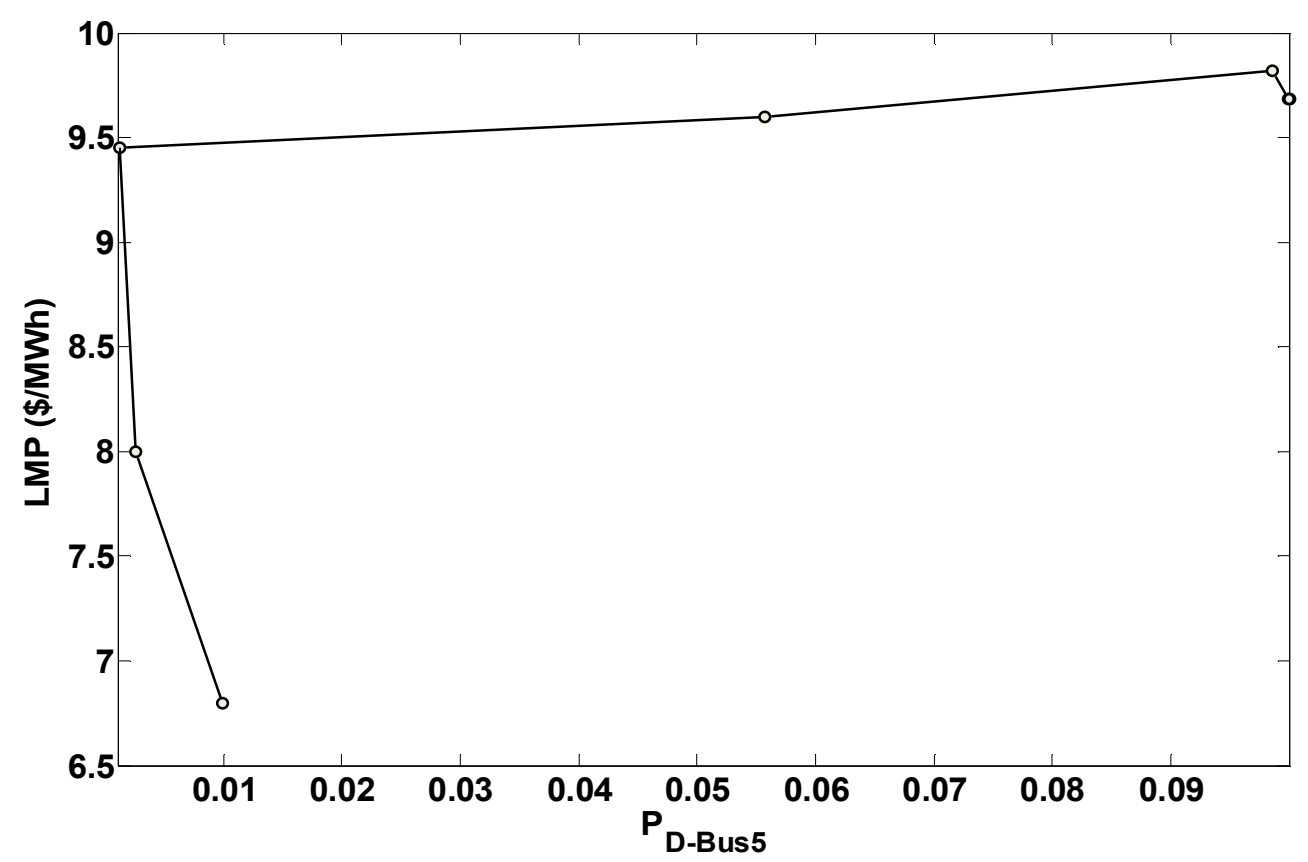

Figure (9) LMP variation for Bus\#5 vs $P_{D}$.

\section{Conclusions}

This paper demonstrates that voltage stability and optimal power flow studies can be performed concurrently. Furthermore, it is shown that incorporating constraints on the current operating point in the maximum distance to collapse problem reduces the space of feasible solutions, resulting in different optimal solutions. The conditions for saddle-node bifurcation versus limit-induced bifurcation are demonstrated. An optimal power flow algorithm that incorporates voltage stability criteria is used on a test system. The results indicate that the algorithm successfully shifts the importance of generation cost minimization and voltage stability security for different loading levels. The future direction of this research is to reformulate the system model to incorporate a distributed slack bus. Furthermore, more numerical simulations will be performed to study the effect of including "operational limits" in a variety of test systems. So from the results the developing improvements to the Voltage Security Constrained OPFs presented. It is important to highlight the fact that the proposed OPF techniques could be readily adapted to determine some of the security costs associated with the operation of a power system, which is of great interest in electricity open market environments. 


\section{References:}

[1] H. W. Dommel and W. F. Tinney, "Optimal power flow solutions, " IEEETransactions on Power Apparatus and Systems, vol. PAS-87, no. 10, October 1965, pp. 18661876.

[2] I. Dobson and etal, "Basic Theoretical Concepts, Voltage Stability Assessment: Concepts, Practices and Tools", IEEE Power Engineering Society, Power System Stability Subcommittee Special Publication, IEEE product number SP101PSS, August 2002.

[3] I. Dobson and H.-D. Chiang, "Towards a theory of voltage collapse in electric power systems", Systems and Control Letters, Vol. 13, 1989, pp. 253-262.

[4] F. Milano, C. A. Canizares, and M. Invernizzi, "Multi-objective optimization for pricing system security in electricity markets," IEEE Trans. Power Syst., vol. 18, no. 2, pp. 596-604, May 2003.

[5] Canizares, and etal, "Comparison of Voltage Security Constrained Optimal Power flow Techniques", Proc. IEEE- PES Summer Meeting, Vancouver, BC, Canada, 2001.

[6] C. A. Canizares, "Calculating optimal system parameters to maximize the distance to saddle node bifurcations," IEEE-Transactions on Circuits and Systems-I: Funda- mental Theory and Applications, vol. 45, no. 3, March 1998, pp. 225-237.

[7] T. Van Cutsem, "A method to compute reactive power margins with respect to voltage collapse," IEEE Trans. Power Systems, vol. 6, no. 1, 1991, pp. 45-156.

[8] C.J. Parker, I.F. Morrison, and D. Sutanto, "Application of an optimization method for determining the reactive margin from voltage collapse in reactive power planning", IEEE Trans. Power Systems, vol. 11, no. 3, August 1996, pp. 1473-1481.

[9] Xie, K., Song, Y.-H., Stonham, J., Yu, E. and Liu, G.: 2000, Decomposition Model and Interior Point Methods for Optimal Spot Pricing of Electricity in Deregulation Environments, IEEE Transactions on Power Systems 15(1), 39-50.

[10] F. Alvarado, I. Dobson, and Y. Hu, "Computation of closest bifurcations in power systems", IEEE Trans. Power Systems, vol. 9, no. 2, May 1994, pp. 918-928.

[11] F. Milano. (2007) PSAT, Matlab-Based Power System Analysis Toolbox. [Online]. Available: http://thundebox.uwaterloo.ca/ fmilano.

\section{Appendix (A)}

IEEE 6-bus sample system data with steady state load flow solution:

This appendix depicts the complete data set for the IEEE 6-bus test system of Figure (2) with details load flow solution:

NETWORK STATISTICS:

\begin{tabular}{|l|c|}
\hline Bus: & $\mathbf{6}$ \\
\hline Lines: & $\mathbf{1 1}$ \\
\hline Generators: & $\mathbf{3}$ \\
\hline Loads: & $\mathbf{3}$ \\
\hline
\end{tabular}

SOLUTION STATISTICS:

\begin{tabular}{|l|c|}
\hline Number of Iterations: & 4 \\
\hline Maximum P mismatch [p.u.] & 0 \\
\hline Maximum Q mismatch [p.u.] & 0 \\
\hline Power rate [MVA] & 100 \\
\hline
\end{tabular}

POWER FLOW RESULTS:

\begin{tabular}{|c|l|l|c|c|l|c|}
\hline Bus & V [p.u.] & Phase [rad] & Pgen [p.u.] & Qgen [p.u.] & Pload [p.u.] & Qload [p.u.] \\
\hline Bus1 & 1.1 & 0.02086 & 0.9 & 0.31823 & 0 & 0 \\
\hline Bus2 & 1.1 & 0 & 1.4914 & 0.63042 & 0 & 0 \\
\hline Bus3 & 1.1 & -0.03551 & 0.6 & 0.71784 & 0 & 0 \\
\hline Bus4 & 1.0377 & -0.0392 & 0 & 0 & 0.92579 & 0.6172 \\
\hline Bus5 & 1.0209 & -0.06997 & 0 & 0 & 1.0345 & 0.72412 \\
\hline Bus6 & 1.0423 & -0.07091 & 0 & 0 & 0.93611 & 0.62407 \\
\hline
\end{tabular}

LINE FLOWS:

\begin{tabular}{|c|c|c|l|c|l|c|}
\hline From Bus & To Bus & Line & P Flow [p.u.] & Q Flow [p.u.] & P Loss [p.u.] & Q Loss [p.u.] \\
\hline Bus2 & Bus3 & 1 & 0.1658 & -0.06641 & 0.00117 & -0.06673 \\
\hline Bus3 & Bus6 & 2 & 0.51358 & 0.5269 & 0.00916 & 0.02284 \\
\hline
\end{tabular}




\begin{tabular}{|l|l|l|l|c|l|c|}
\hline Bus4 & Bus5 & 3 & 0.08317 & -0.03972 & 0.00129 & -0.08219 \\
\hline Bus3 & Bus5 & 4 & 0.25105 & 0.19126 & 0.01112 & -0.03222 \\
\hline Bus5 & Bus6 & 5 & -0.01892 & -0.09796 & 0.00046 & -0.06247 \\
\hline Bus2 & Bus4 & 6 & 0.63546 & 0.36422 & 0.02254 & 0.02221 \\
\hline Bus1 & Bus2 & 7 & 0.10148 & -0.07362 & 0.00105 & -0.04629 \\
\hline Bus1 & Bus4 & 8 & 0.40545 & 0.22737 & 0.00941 & -0.0081 \\
\hline Bus1 & Bus5 & 9 & 0.39307 & 0.16449 & 0.01288 & -0.01926 \\
\hline Bus2 & Bus6 & 10 & 0.46524 & 0.13859 & 0.01417 & -0.01692 \\
\hline Bus2 & Bus5 & 11 & 0.32533 & 0.16669 & 0.01176 & -0.00977 \\
\hline
\end{tabular}

LINE FLOWS:

\begin{tabular}{|c|c|c|c|c|c|c|}
\hline From Bus & To Bus & Line & P Flow [p.u.] & Q Flow [p.u.] & P Loss [p.u.] & Q Loss [p.u.] \\
\hline Bus3 & Bus2 & 1 & -0.16463 & -0.00032 & 0.00117 & -0.06673 \\
\hline Bus6 & Bus3 & 2 & -0.50441 & -0.50405 & 0.00916 & 0.02284 \\
\hline Bus5 & Bus4 & 3 & -0.08188 & -0.04247 & 0.00129 & -0.08219 \\
\hline Bus5 & Bus3 & 4 & -0.23994 & -0.22348 & 0.01112 & -0.03222 \\
\hline Bus6 & Bus5 & 5 & 0.01938 & 0.03549 & 0.00046 & -0.06247 \\
\hline Bus4 & Bus2 & 6 & -0.61292 & -0.34201 & 0.02254 & 0.02221 \\
\hline Bus2 & Bus1 & 7 & -0.10043 & 0.02733 & 0.00105 & -0.04629 \\
\hline Bus4 & Bus1 & 8 & -0.39604 & -0.23547 & 0.00941 & -0.0081 \\
\hline Bus5 & Bus1 & 9 & -0.38019 & -0.18375 & 0.01288 & -0.01926 \\
\hline Bus6 & Bus2 & 10 & -0.45107 & -0.15551 & 0.01417 & -0.01692 \\
\hline Bus5 & Bus2 & 11 & -0.31357 & -0.17646 & 0.01176 & -0.00977 \\
\hline
\end{tabular}

GLOBAL SUMMARY REPORT:

\begin{tabular}{|l|l|}
\hline \multicolumn{2}{|l|}{ TOTAL GENERATION } \\
\hline REAL POWER [p.u.] & 2.9914 \\
\hline REACTIVE POWER [p.u.] & 1.6665 \\
\hline
\end{tabular}

\begin{tabular}{|l|l|}
\hline \multicolumn{2}{|l|}{ TOTAL LOAD } \\
\hline REAL POWER [p.u.] & 2.8964 \\
\hline REACTIVE POWER [p.u.] & 1.9654 \\
\hline
\end{tabular}

\begin{tabular}{|l|c|}
\hline \multicolumn{2}{|c|}{ TOTAL LOSSES } \\
\hline REAL POWER [p.u.] & 0.09501 \\
\hline REACTIVE POWER [p.u.] & -0.29891 \\
\hline
\end{tabular}

\section{Appendix (B)}

The following calculation results show supply and demand bids and the bus data for the market participants, whereas the other shows the line data. Thermal limits were assumed to be twice the values of the line currents at base load conditions for a rating voltage; Finally, maximum and minimum voltage limits are considered to be 1.1 p.u. and 0.9 p.u. and reactive power limits for all three GENCOs are given in MVAr.

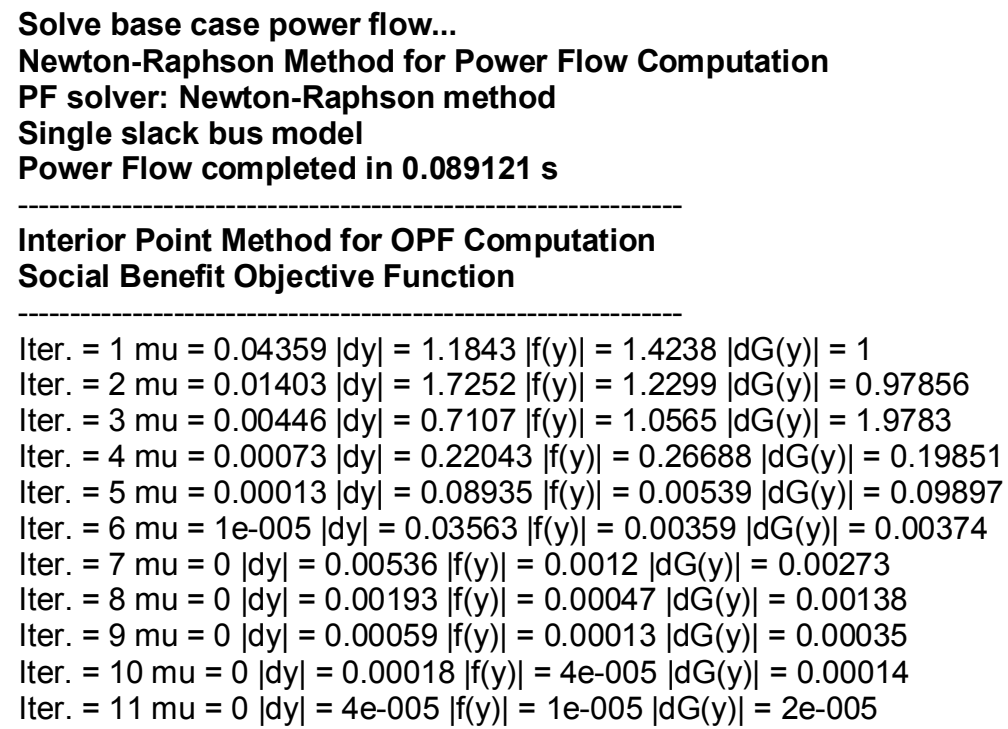


Ahmed: Optimal Power Flow Solution with Maximum Voltage Stability

Iter. $=12 \mathrm{mu}=0|\mathrm{dy}|=1 \mathrm{e}-005|\mathrm{f}(\mathrm{y})|=0|\mathrm{dG}(\mathrm{y})|=1 \mathrm{e}-005$

Iter. $=13 \mathrm{mu}=0|\mathrm{dy}|=0|\mathrm{f}(\mathrm{y})|=0|\mathrm{dG}(\mathrm{y})|=0$

Reactive Powers

\begin{tabular}{|c|c|c|c|}
\hline Bus & Qg [MVar] & Qg max [MVar] & Qg min [MVar] \\
\hline 2 & 76.2060 & 150 & -150 \\
\hline 1 & 44.6233 & 150 & -150 \\
\hline 3 & 72.0844 & 150 & -150 \\
\hline
\end{tabular}

Power Supplies

\begin{tabular}{|l|l|l|l|l|}
\hline Bus & Ps [MW] & Ps max [MW] & Ps min [MW] & Cs [\$/MWh] \\
\hline 1 & 0.0010 & 20 & 0.0010 & 9.7000 \\
\hline 2 & 25.0000 & 25 & 0.0010 & 8.8000 \\
\hline 3 & 20.0000 & 20 & 0.0010 & 7.0000 \\
\hline
\end{tabular}

Power Demands

\begin{tabular}{|c|c|c|c|c|}
\hline Bus & Pd [MW] & Pd max [MW] & Pd min [MW] & Cd [\$/MWh] \\
\hline 4 & 25.0000 & 25 & 0.0010 & 12.0000 \\
\hline 5 & 10.0000 & 10 & 0.0010 & 10.5000 \\
\hline 6 & 8.0694 & 20 & 0.0010 & 9.5000 \\
\hline
\end{tabular}

Power Flow Solution

\begin{tabular}{|c|c|c|c|c|c|c|c|}
\hline Bus & $\begin{array}{c}\mathbf{V} \\
\text { [p.u.] }\end{array}$ & $\begin{array}{c}\text { Theta } \\
{[\mathbf{r a d}]}\end{array}$ & $\begin{array}{c}\mathbf{P} \\
{[\mathbf{M W}]}\end{array}$ & $\begin{array}{c}\mathbf{Q} \\
{[\mathbf{M V a r}]}\end{array}$ & $\begin{array}{c}\text { LMP } \\
{[\mathbf{\$} / \mathbf{M W h}]}\end{array}$ & $\begin{array}{c}\mathbf{N C P} \\
{[\mathbf{\$} / \mathbf{M W h}]}\end{array}$ & $\begin{array}{c}\text { Pay } \\
{[\mathbf{\$} / \mathbf{h}]}\end{array}$ \\
\hline 1 & 1.1000 & 0.0141 & 90.0010 & 44.6233 & 9.0204 & -0.0487 & -811.8424 \\
\hline 2 & 1.1000 & 0.0000 & 164.8754 & 76.2060 & 8.9805 & 0.0000 & -1480.6593 \\
\hline 3 & 1.1000 & -0.0246 & 80.0000 & 72.0844 & 9.1455 & 0.0765 & -731.6399 \\
\hline 4 & 1.0211 & -0.0507 & -115.0000 & -76.6650 & 9.5630 & 0.2074 & 1099.7418 \\
\hline 5 & 1.0129 & -0.0732 & -110.0000 & -77.0000 & 9.6535 & 0.2904 & 1061.8822 \\
\hline 6 & 1.0404 & -0.0676 & -98.0693 & -62.6897 & 9.4284 & 0.2394 & 924.6396 \\
\hline
\end{tabular}

Flows on Transmission Lines

\begin{tabular}{|c|c|c|c|c|c|c|c|}
\hline $\begin{array}{c}\text { From } \\
\text { Bus }\end{array}$ & $\begin{array}{c}\text { To } \\
\text { Bus }\end{array}$ & $\begin{array}{c}\text { lij } \\
\text { [p.u.] }\end{array}$ & $\begin{array}{c}\text { lijmax } \\
\text { [p.u.] }\end{array}$ & $\begin{array}{c}\text { lij margin } \\
\text { [p.u.] }\end{array}$ & $\begin{array}{c}\text { lji } \\
\text { [p.u.] }\end{array}$ & $\begin{array}{c}\text { ljimax } \\
\text { [p.u.] }\end{array}$ & $\begin{array}{c}\text { lji margin } \\
\text { [p.u.] }\end{array}$ \\
\hline 2 & 3 & 0.1169 & 0.3082 & 0.1913 & 0.1045 & 0.3082 & 0.2037 \\
\hline 3 & 6 & 0.7310 & 1.3973 & 0.6663 & 0.7451 & 1.3973 & 0.6522 \\
\hline 4 & 5 & 0.0715 & 0.1796 & 0.1081 & 0.0634 & 0.1796 & 0.1162 \\
\hline 3 & 5 & 0.3373 & 0.6585 & 0.3212 & 0.3673 & 0.6585 & 0.2912 \\
\hline 5 & 6 & 0.1158 & 0.2000 & 0.0842 & 0.0635 & 0.2000 & 0.1365 \\
\hline 2 & 4 & 0.8478 & 1.3740 & 0.5262 & 0.8581 & 1.3740 & 0.5159 \\
\hline 1 & 2 & 0.0813 & 0.2591 & 0.1778 & 0.0623 & 0.2591 & 0.1968 \\
\hline 1 & 4 & 0.4941 & 0.9193 & 0.4252 & 0.5184 & 0.9193 & 0.4009 \\
\hline 1 & 5 & 0.3921 & 0.8478 & 0.4557 & 0.4222 & 0.8478 & 0.4256 \\
\hline 2 & 6 & 0.4327 & 0.9147 & 0.4820 & 0.4511 & 0.9147 & 0.4636 \\
\hline 2 & 5 & 0.3568 & 0.7114 & 0.3546 & 0.3779 & 0.7114 & 0.3335 \\
\hline
\end{tabular}

Totals

Total Losses $=11.807[\mathrm{MW}]$

Bid Losses $=1.932[\mathrm{MW}]$

Total demand $=43.0694[\mathrm{MW}]$

$\mathrm{TTL}=323.069[\mathrm{MW}]$

IMO Pay = 62.1219 $[\$ / \mathrm{h}]$ 


\section{Appendix (C)}

\section{EIGENVALUES OF THE DYNAMIC POWER JACOBIAN MATRIX}

\begin{tabular}{|c|c|c|}
\hline Eigevalue & Real part & Imaginary Part \\
\hline Eig Jlfd1 & -24.1709 & 0 \\
\hline Eig Jlfd2 & 10.4575 & 0 \\
\hline Eig Jlfd3 & 17.9212 & 0 \\
\hline Eig Jlfd4 & 999 & 0 \\
\hline Eig Jlfd5 & 999 & 0 \\
\hline Eig Jlfd6 & 999 & 0 \\
\hline
\end{tabular}

\section{PARTECIPATION FACTORS}

\begin{tabular}{|l|c|c|c|c|c|c|}
\hline & Bus1 & Bus2 & Bus3 & Bus4 & Bus5 & Bus6 \\
\hline Eig Jlfd1 & 0 & 0 & 0 & 0.9993 & 0.00069 & $1 \mathrm{e}-005$ \\
\hline Eig JIfd2 & 0 & 0 & 0 & 0.00061 & 0.80321 & 0.19617 \\
\hline Eig JIfd3 & 0 & 0 & 0 & $8 \mathrm{e}-005$ & 0.1961 & 0.80382 \\
\hline Eig Jlfd4 & 1 & 0 & 0 & 0 & 0 & 0 \\
\hline Eig Jlfd5 & 0 & 1 & 0 & 0 & 0 & 0 \\
\hline Eig Jlfd6 & 0 & 0 & 1 & 0 & 0 & 0 \\
\hline
\end{tabular}

